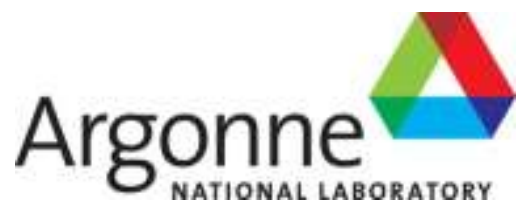

ANL/APS/TB-44, Rev. 6

\title{
Guidelines for Beamline and Front-End Radiation Shielding Design at the Advanced Photon Source
}

Revision 6

Advanced Photon Source 


\title{
About Argonne National Laboratory
}

Argonne is a U.S. Department of Energy laboratory managed by UChicago Argonne, LLC under contract DE-AC02-06CH11357. The Laboratory's main facility is outside Chicago, at 9700 South Cass Avenue, Argonne, Illinois 60439. For information about Argonne and its pioneering science and technology programs, see www.anl.gov.

\section{DOCUMENT AVAILABILITY}

Online Access: U.S. Department of Energy (DOE) reports produced after 1991 and a growing number of pre-1991 documents are available free via DOE's SciTech Connect (http://www.osti.gov/scitech/)

\author{
Reports not in digital format may be purchased by the public from the \\ National Technical Information Service (NTIS): \\ U.S. Department of Commerce National \\ Technical Information Service 5301 \\ Shawnee Rd \\ Alexandra, VA 22312 \\ www.ntis.gov \\ Phone: (800) 553-NTIS (6847) or (703) 605-6000 \\ Fax: (703) 605-6900 \\ Email: orders@ntis.gov
}

\author{
Reports not in digital format are available to DOE and DOE contractors from the \\ Office of Scientific and Technical Information (OSTI): \\ U.S. Department of Energy \\ Office of Scientific and Technical Information \\ P.O. Box 62 \\ Oak Ridge, TN 37831-0062 \\ www.osti.gov \\ Phone: (865) 576-8401 \\ Fax: (865) 576-5728 \\ Email: reports@osti.gov
}

\section{Disclaimer}

This report was prepared as an account of work sponsored by an agency of the United States Government. Neither the United States Government nor any agency thereof, nor UChicago Argonne, LLC, nor any of their employees or officers, makes any warranty, express or implied, or assumes any legal liability or responsibility for the accuracy, completeness, or usefulness of any information, apparatus, product, or process disclosed, or represents that its use would not infringe privately owned rights. Reference herein to any specific commercial product, process, or service by trade name, trademark, manufacturer, or otherwise, does not necessarily constitute or imply its endorsement, recommendation, or favoring by the United States Government or any agency thereof. The views and opinions of document authors expressed herein do not necessarily state or reflect those of the United States Government or any agency thereof, Argonne National Laboratory, or UChicago Argonne, LLC. 
ANL/APS/TB-44, Rev. 6

\section{Guidelines for Beamline and Front-End Radiation Shielding Design at the Advanced Photon Source}

Revision 6

prepared by

P. Fernandez and S. Davey

Advanced Photon Source, Argonne National Laboratory

December 2015 


\section{Revision History}

\begin{tabular}{|c|c|c|c|}
\hline Revision 1 & $\begin{array}{l}\text { September } \\
2003\end{array}$ & & Authored by P.K. Job, APS Radiation Physicist \\
\hline Revision 2 & May 2005 & $\begin{array}{l}\text { Revisions by: } \\
\text { P. K. Job }\end{array}$ & $\begin{array}{l}\text { 1) Section } 3.1-\text { Moliere radius for lead corrected } \\
\text { from } \sim 15 \mathrm{~mm} \text { to } \sim 12 \mathrm{~mm} \text {. } \\
\text { 2) Section } 3.1 .1-\text { The minimum margin between } \\
\text { a bremsstrahlung extremal ray and a tungsten } \\
\text { stop edge changed from } 35 \mathrm{~mm} \text { to } 30 \mathrm{~mm} \text {. }\end{array}$ \\
\hline Revision 3 & $\begin{array}{l}\text { September } \\
2008\end{array}$ & $\begin{array}{l}\text { Revisions by: } \\
\text { P. Fernandez }\end{array}$ & $\begin{array}{l}\text { 1) Revision History added and title page revised. } \\
\text { 2) Section } 3.1 .3 \text { - The minimum margin between } \\
\text { a bremsstrahlung extremal ray and the edge } \\
\text { of a tungsten collimator changed from } 35 \mathrm{~mm} \\
\text { to } 30 \mathrm{~mm}\end{array}$ \\
\hline Revision 4 & $\begin{array}{l}\text { October } \\
2012\end{array}$ & $\begin{array}{l}\text { Revisions by: } \\
\text { P. Fernandez } \\
\text { and S. Davey }\end{array}$ & $\begin{array}{l}\text { 1) Changed Beamline Review Committee to } \\
\text { Beamline Safety Design Review Steering } \\
\text { Committee } \\
\text { 2) Changed AOD to AES } \\
\text { 3) Changed APS Radiation Scientist to } \\
\text { BSDRSC Chair } \\
\text { 4) Clarified } 1 \mathrm{~m}^{2} \text { supplemental shielding to } 1 \\
\mathrm{~m} \text { by } 1 \mathrm{~m} \\
\text { 5) Noted beam transport shielding } \\
\text { calculation for } 10 \mathrm{~cm} \text { diameter pipe }\end{array}$ \\
\hline Revision 5 & $\begin{array}{l}\text { September } \\
2014\end{array}$ & $\begin{array}{l}\text { Revisions by } \\
\text { S. Davey }\end{array}$ & $\begin{array}{l}\text { 1) In Section } 1 \text { ALARA goals and in Section } \\
3.2 .1 \text { replaced "mrem/yr" units with "mSv/yr } \\
\text { (mrem/yr)" or " } \mu \text { Sv/h (mrem/h)" units } \\
\text { 2) Clarified the last sentence of the } 1 \mathrm{st} \\
\text { paragraph of section } 3.1 .1 \\
\text { 3) Clarified the last sentence of the } 1 \mathrm{st} \\
\text { paragraph of section } 3.1 .2 \text { and section } 1,2 \text { nd } \\
\text { paragraph from } 2 \mathrm{mSv} / \mathrm{yr} \text { to } 2 \mathrm{mSv} / \mathrm{yr}(200 \\
\text { mrem/yr) }\end{array}$ \\
\hline Revision 6 & $\begin{array}{l}\text { December } \\
2015\end{array}$ & $\begin{array}{l}\text { Revision by } \\
\text { S. Davey }\end{array}$ & $\begin{array}{l}\text { 1) In Section 2, last sentence of } 1^{\text {st }} \text { paragraph, } \\
\text { changed "AES Division Director (or his } \\
\text { authorized designee)" to "APS management" } \\
\text { 2) In Section 4, replaced last reference }\end{array}$ \\
\hline
\end{tabular}




\section{Table of Contents}

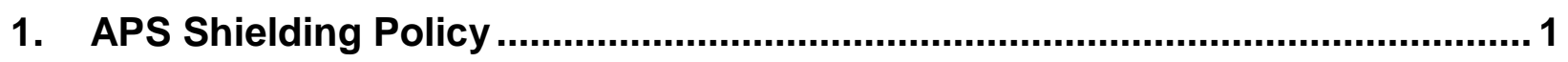

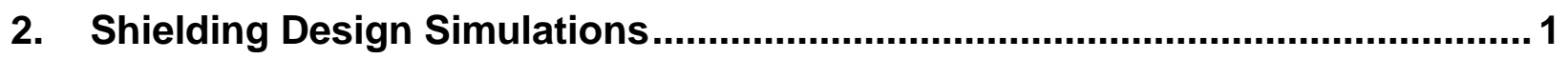

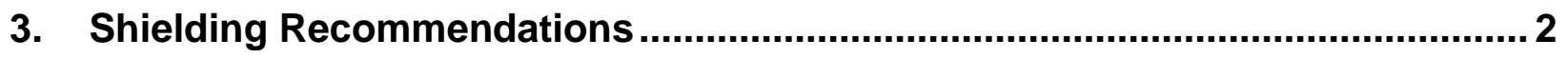

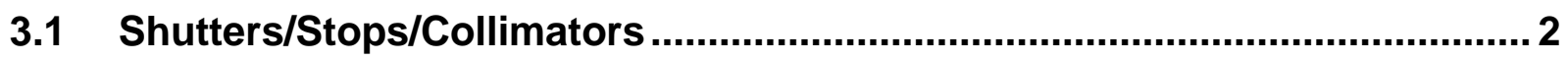

3.1.1 White Beam Shutters/Stops.................................................................... 3

3.1.2 Monochromatic/ Pink Beam Shutters .................................................. 4

3.1.3 Bremsstrahlung Collimators ............................................................... 4

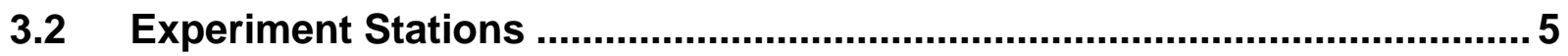

3.2.1 Insertion Device White Beam Stations …............................................. 5

3.2.2 Bending Magnet White Beam Stations ............................................... 6

3.2.3 Monochromatic/Pink Beam Stations.................................................. 6

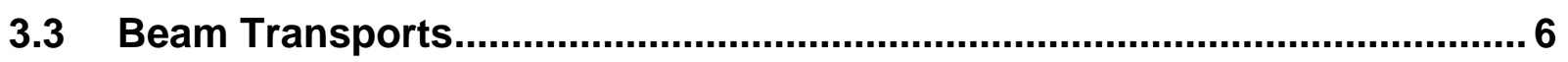

3.3.1 White Beam Transport .........................................................................

3.3.2 Monochromatic Beam Transport ............................................................ 7

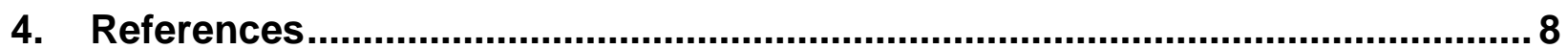





\section{Guidelines for Beamline and Front-End Radiation Shielding Design at the Advanced Photon Source}

\section{APS Shielding Policy}

Shielding for the APS will be such that the individual radiation worker dose will be as low as reasonably achievable (ALARA). The ALARA goals for the APS are to keep the total of the work-related radiation exposure (exposure coming from other than natural or medical sources) as far below 5 person $\mathrm{mSv} / \mathrm{yr}$ (500 person-mrem/yr), collective total effective dose equivalent, as reasonably achievable.

For an individual APS radiation worker, the goal is to keep the maximum occupational total effective dose equivalent of any one employee as far below $2 \mathrm{mSv} / \mathrm{yr}$ (200 mrem/year) as reasonably achievable.

The ALARA goal for APS beamline scientists is to keep the total of the work-related radiation exposure (exposure coming from other than natural or medical sources) as far below 1 person $\mathrm{mSv} / \mathrm{yr}$ (100 person-mrem/yr), collective total effective dose equivalent, as reasonably achievable.

For an individual APS beamline scientist, the goal is to keep the maximum occupational total effective dose equivalent of any one scientist as far below $0.5 \mathrm{mSv} / \mathrm{yr}(50 \mathrm{mrem} / \mathrm{yr})$ as reasonably achievable.

The dose is actively monitored by the radiation monitors on the storage ring wall in each sector and by the frequent area surveys performed by the health physics personnel. For cases in which surveys indicate elevated hourly dose rates that may impact worker exposure, additional local shielding is provided to reduce the radiation field to an acceptable level. Passive area monitors are used throughout the facility to integrate doses in various areas. The results are analyzed for trends of increased doses, and shielding in these areas is evaluated and improved, as appropriate.

The APS policy for on-site nonradiation workers in the vicinity of the APS facilities requires that the average nonradiation worker dose be below $0.2 \mathrm{mSv} / \mathrm{yr}(20 \mathrm{mrem} / \mathrm{yr})$. In addition, the dose at the site boundary from all pathways is required to be below 0.1 $\mathrm{mSv} / \mathrm{yr}(10 \mathrm{mrem} / \mathrm{yr})$. For future modifications of the facility, the doses shall be evaluated and additional shielding provided to meet the policy requirements.

\section{Shielding Design Simulations}

Shielding guidelines and requirements have been developed through extensive simulations using the EGS4 ${ }^{1}, \mathrm{PHOTON}^{2}$, and $\mathrm{STAC}^{3}$ shielding computer programs and have been published to provide the basis for the beamline and front-end shielding designs in LS- $141^{4}$, TB- $5^{5}$, TB- ${ }^{6}$, TB- $20^{7}$, TB- $21^{8}$, and TB- $44^{9}$. The neutron dose simulations for the first optics enclosure (FOE) and for the experiment floor were done by the $\mathrm{PICA}^{10}$ neutron shield program and later have been confirmed by 
measurements ${ }^{11}$. However, the neutron dose hazard on the experiment floor is found to be insignificant for all credible scenarios and neutron shielding on the floor has not been recommended other than for specific instances. These simulations also form the basis for the ionizing radiation hazard analysis described in the Safety Assessment Document (SAD) of the APS. Please refer to these documents for additional information on simulation procedures and geometry. The Beamline Safety Design Review Steering Committee will evaluate all beamline and front-end shielding component designs to confirm the implementation of the criteria presented in the references in section 4. All designs of beamline and front-end components that fall within the defined envelope will not require specific additional safety review. The designs that fall outside the defined envelope will require additional independent review at the design stage. The sign-offs of the BSDRSC Chair and APS management (per the APS Design Review Policy, APS 000031) will attest that the review procedures have been successfully completed.

The shielding design for the APS was based on conservative assumptions, including several types of operations that involve normal beam-loss mechanisms, as well as certain abnormal beam-loss scenarios. These scenarios, listed in the above-mentioned shielding documents, were drawn from experiences and assumptions used at existing accelerator and synchrotron radiation facilities. The radiation dose limits are less than the DOE guidelines for both on-site and off-site exposures. Design standards for new facilities require that the individual worker dose should be less than $5 \mathrm{mSv} / \mathrm{yr}$ (500 $\mathrm{mrem} / \mathrm{yr})$ and ALARA. This effectively reduces the design dose rate to $2.5 \mu \mathrm{Sv} / \mathrm{h}(0.25$ $\mathrm{mrem} / \mathrm{h}$ ) for occupational exposure of 2000 hours/year.

For each shielding situation, the synchrotron and bremsstrahlung shielding have been calculated for a representative geometry. The shielding requirements for both bremsstrahlung and synchrotron radiation are given. The shielding simulations for bremsstrahlung were done using the EGS4 program and for synchrotron radiation using the PHOTON/STAC8 programs. In most cases, one of the sources (bremsstrahlung/synchrotron radiation) dominates for the shielding requirement and the contribution of the other becomes negligible, thus the calculated shielding for the dominant source is implemented. The insertion device spectrum was calculated by the $\mathrm{XOP}^{12}$ program. All calculations were done at $300 \mathrm{~mA}$ of beam current and $7 \mathrm{GeV}$ electron beam energy. For the monochromatic shielding calculations, a conservative bandpass value of $0.1 \%$ was assumed for the monochromator. A tenth value layer of additional shielding is added to all calculated synchrotron radiation shielding thicknesses. Also, all the doses are scored in the ICRU tissue on contact, instead of at a distance of $30 \mathrm{~cm}$ from the dose point. Thus the shielding is designed to meet or exceed the criteria to ensure that occupational radiation doses are ALARA.

\section{Shielding Recommendations 3.1 Shutters/Stops/Collimators}

A shutter is a remotely actuated device, and a stop is a non-movable, or manually movable, secured device to stop the radiation beam. While the shutter/stop is in the closed state, it must completely block the possible line of sight of the radiation, including 
the bremsstrahlung shower, from upstream as seen from downstream. The analytical shower theory ${ }^{13}$ and the measurements on $6.3 \mathrm{GeV}$ electromagnetic shower in lead and concrete $^{14}$ show that a longitudinal depth of 20 radiation lengths and a transverse dimension of three Moliere Radii is required to contain $99 \%$ of the shower within the blocks in which it is generated. Therefore, for the design of the labyrinths in the hard metal of a bremsstrahlung/white beam shutter, a labyrinth step size of approximately three Moliere Radii of transverse dimensions with a longitudinal depth of approximately 20 radiation lengths is recommended in order to contain the bremsstrahlung shower within the shutter. The Moliere Radius for lead is $\sim 12 \mathrm{~mm}$; for tungsten it is $\sim 8 \mathrm{~mm}$. The radiation length for lead is $5.6 \mathrm{~mm}$, and for tungsten it is $3.5 \mathrm{~mm}^{15}$.

\subsubsection{White Beam Shutters/Stops}

All APS shutters (for white and monochromatic beams) are designed to be redundant. Two shielding blocks will stop bremsstrahlung and the synchrotron beam when the shutter is closed, although any one shutter is designed to provide adequate shielding. Also, the personnel safety system (PSS) will detect any shutter failure through redundant switches and will take appropriate measures to shut off the beam during a fault condition. All shutters are designed in the 'fail safe' mode such that in the event of a power, communication, or mechanical system failure, the shutter will come to a closed state and will remain in the closed state. Fixed stops and administratively-controlled manually-secured movable stops are not required to have redundant shielding blocks.

Table 1. Recommendations for shutter/stop thickness

\begin{tabular}{|l|c|c|}
\hline \multicolumn{1}{|c|}{ Beam Type } & $\begin{array}{c}\text { Tungsten } \\
\text { Thickness }\end{array}$ & Lead Thickness \\
\hline ID White Beam & $180 \mathrm{~mm}$ & $300 \mathrm{~mm}$ \\
\hline BM White Beam & $180 \mathrm{~mm}$ & $300 \mathrm{~mm}$ \\
\hline ID Mono/Pink Beam & $60 \mathrm{~mm}$ & (a) \\
\hline BM Mono/Pink Beam & $21 \mathrm{~mm}$ & (a) \\
\hline
\end{tabular}

(a) The thickness of monochromatic beam stops needs to be evaluated based on the monochromatic beam specifications of each beamline.

Synchrotron radiation may place a significant thermal load on beamline components, including shutters and stops. The beamline shall be designed to ensure that thermal protection is provided, if necessary, in order that the shielding cannot be compromised. Such a thermal shutter/stop is located prior to the lead/tungsten shielding blocks. This is achieved in the beamlines and in the front-ends by copper photon stops. The thermal shutter/stop need not be redundant if the water coolant flow/pressure is monitored by the PSS.

The thickness of white beam stops and shutters at the APS are calculated from the EGS4 simulation. The thickness of the stops/shutters is calculated for a dose rate of 
$2.5 \mu \mathrm{Sv} / \mathrm{h}(0.25 \mathrm{mrem} / \mathrm{h})$ at the downstream side of the stop/shutter on contact. Table 1 summarizes recommendations evolved from the simulations for the thickness of shutters/stops at the APS beamlines and the front-ends. The recommended thickness of white beam stops and shutters is $300 \mathrm{~mm}$ of lead or $180 \mathrm{~mm}$ of tungsten. The transverse dimensions of the shutters/stops are determined from the primary bremsstrahlung ray tracing. The extremal ray in the case of primary bremsstrahlung ray-tracing should not be closer than $45 \mathrm{~mm}$ from the lateral edge of the lead or $30 \mathrm{~mm}$ from that of the tungsten shield block.

\subsubsection{Monochromatic/ Pink Beam Shutters}

The thickness of each monochromatic tungsten beam shutter, which is redundant, is calculated by the STAC8 shielding program. The thickness is specified to be $60 \mathrm{~mm}$ for ID sources and $21 \mathrm{~mm}$ for bending magnet sources (Table 1). The thickness of monochromatic beam stops needs to be evaluated based on the monochromatic beam specifications of each beamline. Monochromatic stops can take credit for the station wall shielding along the projected beam path.

The pink beam shutters/stops in the beamlines have the same shielding requirements as the monochromatic beam components. However, for thermal load considerations, the white beam case applies.

In the case of tungsten integral shutters (white beam stop-mono-beam pass), for the monochromatic beam aperture an offset of $8 \mathrm{~mm}$ or more is safe for the extremal bremsstrahlung ray from the edge of the mono-aperture to minimize the cross talk. For the lead apertures, this offset is $15 \mathrm{~mm}$.

\subsubsection{Bremsstrahlung Collimators}

Bremsstrahlung/whitebeam collimators must have the same thickness of heavy metal as bremsstrahlung stops/shutters with the appropriate aperture. The collimators must completely block the possible line of sight of the radiation, including the bremsstrahlung shower, from the upstream as seen from the downstream. Transverse dimensions of the collimators are determined from the primary bremsstrahlung ray tracing. The extremal ray in the case of primary bremsstrahlung ray tracing should not be closer than $45 \mathrm{~mm}$ from the lateral edge of the lead or $30 \mathrm{~mm}$ from that of the tungsten collimator block. If the collimators are built from straight-edged bricks, care must be taken to avoid straight seams in the direction of the beam as a safe practice. It is recommended to use interlocking bricks or bricks with appropriate offset (preferably greater than three Moliere Radii) such that straight seams in the direction of the beam are excluded. The seams should be configured to provide greater than $50 \%$ of the total thickness of the collimator in the direction of the beam. 


\subsection{Experiment Stations}

Table 2 summarizes the shielding recommendations for the experiment stations at the APS. These recommendations are evolved from the EGS4, PHOTON, and STAC8 simulations and are reported in detail in TB-7, TB-20, and TB-21. The thickness of the experiment station panels is calculated for a dose rate of $2.5 \mu \mathrm{Sv} / \mathrm{h}(0.25 \mathrm{mrem} / \mathrm{h})$ at the outside surface on contact. The recommendations given in this report reflect an additional tenth value layer to the calculated thickness for the synchrotron radiation shielding.

Table 2. Shielding recommendations for experiment stations (Pb thickness)

\begin{tabular}{|l|c|c|c|c|}
\hline \multicolumn{1}{|c|}{ Station Type } & $\begin{array}{c}\text { Upstream } \\
\text { Panel }\end{array}$ & Lateral Panel & Roof & $\begin{array}{c}\text { Downstream } \\
\text { Panel }\end{array}$ \\
\hline ID White Beam & $19 \mathrm{~mm}$ & $19 \mathrm{~mm}$ & $12 \mathrm{~mm}$ & $\begin{array}{c}50 \mathrm{~mm} \\
\text { (100 locally) }\end{array}$ \\
\hline BM White Beam & $8 \mathrm{~mm}$ & $8 \mathrm{~mm}$ & $6 \mathrm{~mm}$ & $\begin{array}{c}9 \mathrm{~mm} \\
(24 \text { locally })\end{array}$ \\
\hline ID Mono/Pink Beam & $10 \mathrm{~mm}$ & $10 \mathrm{~mm}$ & $6 \mathrm{~mm}$ & $12 \mathrm{~mm}$ \\
\hline BM Mono/Pink Beam & $6 \mathrm{~mm}$ & $6 \mathrm{~mm}$ & $4 \mathrm{~mm}$ & $7 \mathrm{~mm}$ \\
\hline
\end{tabular}

\subsubsection{Insertion Device White Beam Stations}

To shield the insertion device (ID) white beam stations and first optics enclosures (FOEs) for synchrotron radiation only requires 19 and $16 \mathrm{~mm}$ of lead for the back wall and for the lateral wall, respectively. A $10 \%$ occupancy rate for the roof is assumed and will be shielded for $25 \mu \mathrm{Sv} / \mathrm{hr}(2.5 \mathrm{mrem} / \mathrm{h})$, which requires $12 \mathrm{~mm}$ of lead.

The lead thickness for bremsstrahlung only shielding was calculated to be $114.4 \mathrm{~mm}$ at the lowest angle spot on the back wall not shadowed by the tungsten stop. The secondary bremsstrahlung scattering, and hence the required shielding, drops quickly as the angle from the primary beam increases. It is recommended that appropriate collimators be placed along the beamline to shadow the back wall from the low-angle scatter of components in the beam. With the use of collimators, the recommended shielding for the entire back wall is $50 \mathrm{~mm}$ of lead. An approximately $1 \mathrm{~m}$ by $1 \mathrm{~m}$ portion of the back wall, centered on the direct beam, will require an additional $50 \mathrm{~mm}$ of lead. This can also be satisfied with appropriate design of the guillotines.

To summarize, the bremsstrahlung shielding dominates for the back wall, and the synchrotron radiation dominates for the lateral wall and the roof. Lead shielding of $50 \mathrm{~mm}$ is needed for the entire back wall, with an additional $50 \mathrm{~mm}(100 \mathrm{~mm}$ total) for the central portion of the back wall, which can be satisfied with appropriate guillotines. Lead shielding of $19 \mathrm{~mm}$ is needed for the lateral wall, and $12 \mathrm{~mm}$ is needed for the roof. 


\subsubsection{Bending Magnet White Beam Stations}

The bending magnet white beam stations and FOEs require 9,8 , and $6 \mathrm{~mm}$ of lead for the back wall, lateral wall, and roof, respectively, for synchrotron radiation only. The bremsstrahlung for a bending magnet beamline compared to that for an ID beamline is reduced by the effective straight section length, in the line of sight of the beamline. Dividing the recommended ID shielding thicknesses by an appropriate factor leads to shielding of $9 \mathrm{~mm}$ for the back wall for bremsstrahlung only. An area of approximately $1 \mathrm{~m}$ by $1 \mathrm{~m}$ centered around the direct beam at the back wall will require an additional $15 \mathrm{~mm}$ (a total of $24 \mathrm{~mm}$ ) of lead shielding. As with the ID FOE, collimators should be used, based on the bremsstrahlung ray tracing, to reduce the line of sight to the back wall.

In summary, lead thicknesses of $9 \mathrm{~mm}$ for the back wall ( $24 \mathrm{~mm}$ locally), $8 \mathrm{~mm}$ for the lateral wall, and $6 \mathrm{~mm}$ for the roof are recommended for the bending magnet white beam stations (Table 2).

\subsubsection{Monochromatic/Pink Beam Stations}

For the monochromatic station shielding simulations, a conservative bandpass value of $0.1 \%$ was assumed for the monochromator in the STAC8 calculations. Most of the radiation that needs to be shielded results from the higher harmonics of the transmitted beam. It is assumed that the bremsstrahlung radiation has been stopped upstream.

The insertion device monochromatic stations require lead shielding of $12.5 \mathrm{~mm}$ for the back (downstream) wall, $10 \mathrm{~mm}$ for the front (upstream) and lateral walls, and $6 \mathrm{~mm}$ for the roof.

The bending magnet monochromatic stations require lead shielding of $7 \mathrm{~mm}$ for the back wall, $6 \mathrm{~mm}$ for the front and lateral walls, and $4 \mathrm{~mm}$ for the roof (Table 2).

The pink beam experimental stations have the same shielding requirements as the monochromatic beam stations. However, for the thermal load considerations, pink beam should be treated as white beam.

\subsection{Beam Transports}

Simulations were done by PHOTON and STAC8 shielding programs using air as the scatterer from the beam transport. Shielding thickness for beam transport was calculated assuming a conservative dose of $25 \mu \mathrm{Sv} / \mathrm{h}(2.5 \mathrm{mrem} / \mathrm{h})$ on contact in the event of a complete loss of vacuum in the transport. The calculation also assumed 10 $\mathrm{cm}$ diameter transport beampipes (see TB-7 section 3.2.3). Table 3 summarizes shielding recommendations for beam transports at the APS. 


\subsubsection{White Beam Transport}

It is recommended that, whenever possible, white beam transport be minimized outside the experiment stations. If deemed necessary, a careful ray trace should be carried out, and collimation should be used to prevent the transport from being hit by the bremsstrahlung or synchrotron radiation beam. Wherever possible, slits, shutters, and any other components that might be struck by the beam should be provided with additional shielding.

To shield the ID beamline white beam transport against synchrotron radiation only, $12 \mathrm{~mm}$ of lead is needed for air scattering. For a solid scatterer, $21 \mathrm{~mm}$ of lead will be needed for synchrotron radiation only. For the solid scattering of secondary bremsstrahlung, $45 \mathrm{~mm}$ of lead is required in the beam transport outside the beamline enclosures.

For the bending magnet white beam transport, $6 \mathrm{~mm}$ of lead is needed for air and $11 \mathrm{~mm}$ for solid scatterers for synchrotron radiation only. For the solid scattering of secondary bremsstrahlung, $12 \mathrm{~mm}$ of lead is required in the beam transport outside the beamline enclosures.

Table 3. Shielding recommendations for beam transport ( $\mathrm{Pb}$ thickness for a $10 \mathrm{~cm}$ diameter beampipe)

\begin{tabular}{|l|c|c|c|}
\hline \multicolumn{1}{|c|}{ Beam Type } & $\begin{array}{c}\text { Air as } \\
\text { Scatterer }\end{array}$ & $\begin{array}{c}\text { Solid Scatterer } \\
\text { (Synch. Radiation) }\end{array}$ & $\begin{array}{c}\text { Solid Scatterer } \\
\text { (Bremsstrahlung) }\end{array}$ \\
\hline ID White Beam & $12 \mathrm{~mm}$ & $21 \mathrm{~mm}$ & $45 \mathrm{~mm}$ \\
\hline BM White Beam & $6 \mathrm{~mm}$ & $11 \mathrm{~mm}$ & $12 \mathrm{~mm}$ \\
\hline ID Mono/Pink Beam & $8 \mathrm{~mm}$ & $12 \mathrm{~mm}$ & (b) \\
\hline BM Mono/Pink Beam & $5 \mathrm{~mm}$ & $7 \mathrm{~mm}$ & (b) \\
\hline
\end{tabular}

(b) Mono/Pink Beam does not contain a bremsstrahlung component.

\subsubsection{Monochromatic Beam Transport}

For an ID with a $0.1 \%$ bandpass monochromator, the required lead shielding on transport is $8 \mathrm{~mm}$ for vacuum loss scattering. Shielding of $12 \mathrm{~mm}$ lead is recommended for areas in which there are potential solid scatterers.

Likewise, for the bending magnet monobeam transport, the recommended lead shielding for vacuum loss is $5 \mathrm{~mm}$ and for potential solid scatterers is $7 \mathrm{~mm}$.

The pink beam transports have the same shielding requirements as the monochromatic beam transport other than for thermal load considerations. 


\section{References}

1. EGS4 Code System, SLAC265 (1985).

2. PHOTON Shielding Program, NIM A266 (1988).

3. Y. Asano, Private Communication (1998).

4. H. Moe, Radiological Considerations of APS, APS-LS-141 (1991).

5. T. Kuzay, Functional Description of APS Front-Ends, APS-TB-5 (1993).

6. N. Ipe, et al., Guide to Beamline Radiation Shielding, APS-TB-7 (1993).

7. P. K. Job, et al., Bremsstrahlung Scattering Calculations, APS-TB-20 (1994).

8. W. Yun, et al., Radiation Shielding of Insertion Device Beamlines, APS-TB-21 (1995).

9. P. K. Job, Guidelines for Beamline Radiation Shielding Design, APS-TB-44 (2002). Note - This will be suspended by this document and no longer available.

10. T. Gabriel, PICA, Intra-nuclear Cascade Calculation, ORNL 4687 (1971).

11. M Pisharody et al., Dose Measurements of Bremsstrahlung Produced Neutrons, APS-LS-269 (1998).

12. R. Dejus, Private Communication (1996).

13. B. Rossi, High Energy Particles, Prentice Hall (1952), Chapter 5.

14. G. Bathow, Measurements of $6.3 \mathrm{GeV}$ Electromagnetic Cascades, Nucl. Phys., B2, 669 (1967).

15. LS-295, Radiological Considerations for the Operation of the Advanced Photon Source Storage Ring - Revised (1997). 



\section{Argonne}

Advanced Photon Source

Argonne National Laboratory

9700 South Cass Avenue, Bldg. 401

Argonne, IL 60439

www.anl.gov 